\title{
SUCCESSFUL TREATMENT OF INTRACARDIAC AND PULMONARY THROMBI IN BEHÇET'S DISEASE WITH ORAL ANTICOAGULANT AND IMMUNOSUPPRESSIVE THERAPY
}

\author{
Uğur Canpolat ${ }^{1}$, Hikmet Yorgun ${ }^{2}$, Ali Akdoğan², Kudret Aytemir ${ }^{1}$
}

Hacettepe University Faculty of Medicine, Ankara, Turkey: Department of Cardiology ${ }^{1}$, Department of Internal Medicine, Rheumatology Unit ${ }^{2}$

Summary: Behçet's disease is a multisystem chronic inflammatory disease generally presenting as recurrent oral-genital ulcers and uveitis. Vascular involvement is a common presentation. However, cardiac involvement is rare in this disorder. In this case report, we present a large right ventricular thrombus detected both in computed tomography and echocardiography in a 32 year-old male patient with complaints of fever, haemoptysis and weight loss. Intracardiac thrombus showed both clinical and radiological regression with oral anticoagulant and immunosuppressive therapy.

Key words: Behçet's disease; Echocardiography; Thrombus

\section{Introduction}

Behçet's disease (BD) is a vasculitic disease characterized by recurrent oral and genital ulcers, skin eruptions and uveitis. This inflammatory disorder has a multisystem involvement and generally affects young adults of Mediterranean and Middle Eastern countries. The spectrum of cardiac involvement includes pericarditis, cardiomyopathy, autonomic dysfunction, endocarditis, endomyocardial fibrosis, intracavitary thrombosis and coronary artery disease. Although cardiac involvement of BD is rare, poor prognosis and higher mortality rates regarding cardiovascular complications requires great attention (1-3). In this paper, we report a case of large intracardiac thrombus which was resolved completely with corticosteroid, colchicine, interferon alpha, cyclophosphamide and oral anticoagulant therapy.

\section{Case}

A 32-year-old male patient admitted to emergency department of our hospital with cough, dyspnea and sweating. He suffered from haemoptysis after hard cough for two weeks with a weight loss of $10 \mathrm{~kg}$ in the last 6 months. He has no cardiovascular or systemic illness and was not taking any medication. On physical examination, his blood

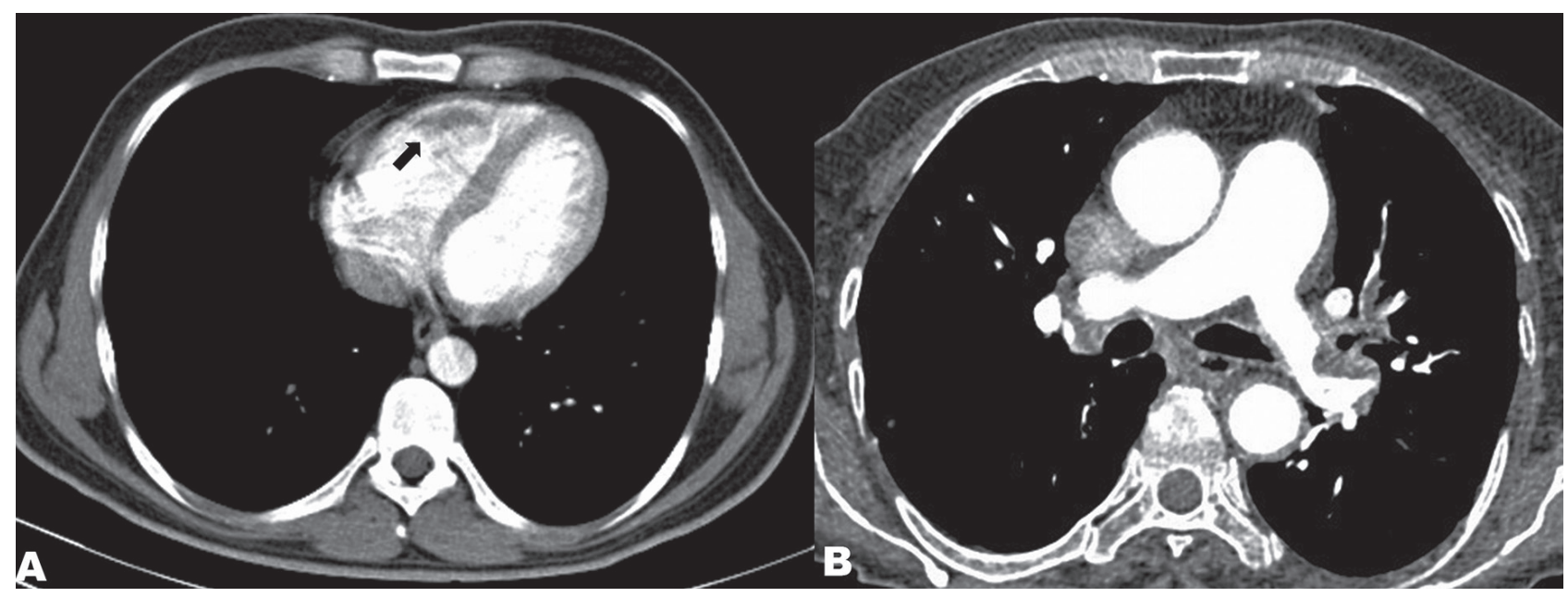

Fig. 1: Computerized tomography showing hypodense lesion relevant with thrombus $(14 \times 33 \mathrm{~mm})$ at apex of the right ventricle 
pressure was $110 / 70 \mathrm{mmHg}$, he was subfebrile $\left(37.9^{\circ} \mathrm{C}\right)$, had tachypnea (24/min) and tachycardia (112/min). Cardiac and pulmonary examinations were in normal limits. Oral examination showed aphtous ulcers and examination of extremities revealed pustules in both antecubital area. A scar of the genital ulcer was identified on the scrotum. Laboratory tests revealed a normal blood chemistry and with an increased white blood cell count $\left(14 \times 10^{3} / \mathrm{ul}\right.$, normal: $\left.4-10 \times 10^{3} / \mathrm{ul}\right)$, eryhrocyte sedimentation rate (70 mm/hr, normal: $0-20)$, C-reactive protein $(1.5 \mathrm{mg} / \mathrm{dl}$, normal: 0-0.8) and D-dimer (1.09 $\mu \mathrm{g} / \mathrm{ml}$, normal: 0-0.48). Electrocardiography showed sinus tachycardia and chest $\mathrm{X}$-ray was normal. Pulmonary thromboembolism was suspected as an initial diagnosis and computed tomography pulmonary angiography revealed thrombus in posterobasal segment of left lower lobe branch of the pulmonary artery, hypodense lesion compatible with thrombus $(14 \times 33 \mathrm{~mm})$ in right ventricle and multiple opacities with suspected infarcts (Figure 1). Transthoracic and transesophageal echocardiography showed a mobile mass moving through RVOT (Figure 2). He has no family history for thrombophilia or BD. Factor V Leiden mutation test was negative, however prothrombin 20210A mutation test

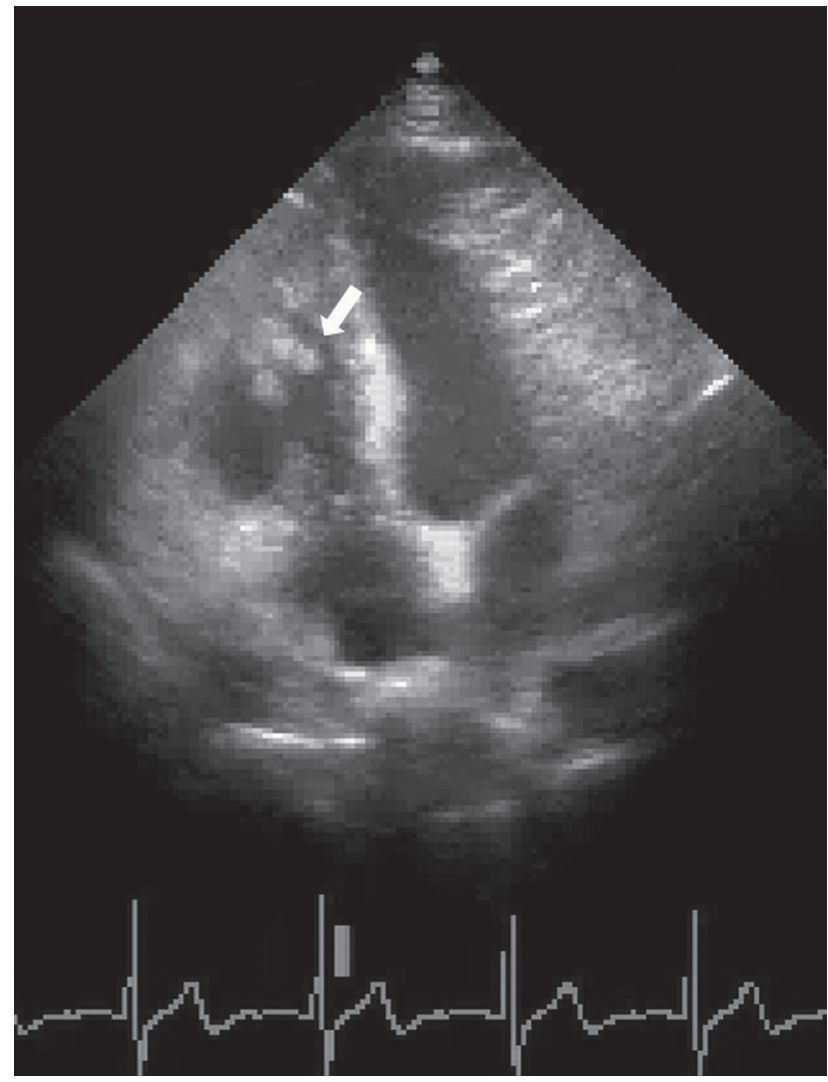

Fig. 2: Transthoracic echocardiography showed a mobile mass originating from right ventricle apex was heterozygote and methylene-tetrahydrofolate reductase (MTHFR) C677T mutation was homozygote positive. Additionally, plasma homocysteine level was $41.5 \mu \mathrm{mol} / 1$ (upper reference limit: $15 \mu \mathrm{mol} / 1$ ). The antiphospholipid, anticardiolipine, antinuclear antibodies and anti-dsDNA were negative. The bilateral lower extremity doppler ultrasonographic examination revealed normal venous and arterial system. So, the patient was diagnosed as Behçet disease with cardiac and pulmonary involvement.

We opted for a treatment based on unfractioned heparin under control of activated partial thromboplastin time (aPTT). Thereafter, we concomitantly initiated intravenous pulse metilprednisolone (1000 mg), cyclophosphamide $(500 \mathrm{mg})$, interferone alpha 2A (9 million units, three times a week), colchicine ( $1.5 \mathrm{mg} /$ day) with heparin therapy. He was hospitalized for a week. His haemoptysis and cough disappeared. During discharge he was anticoagulated with warfarin. Consequently 1 month later right ventricular thrombus had been disappeared on transthoracic echocardiography (Figure 3), also thoracic computerized tomography confirmed the disappearance of the right ventricular thrombus and reduced pulmonary thrombus burden.

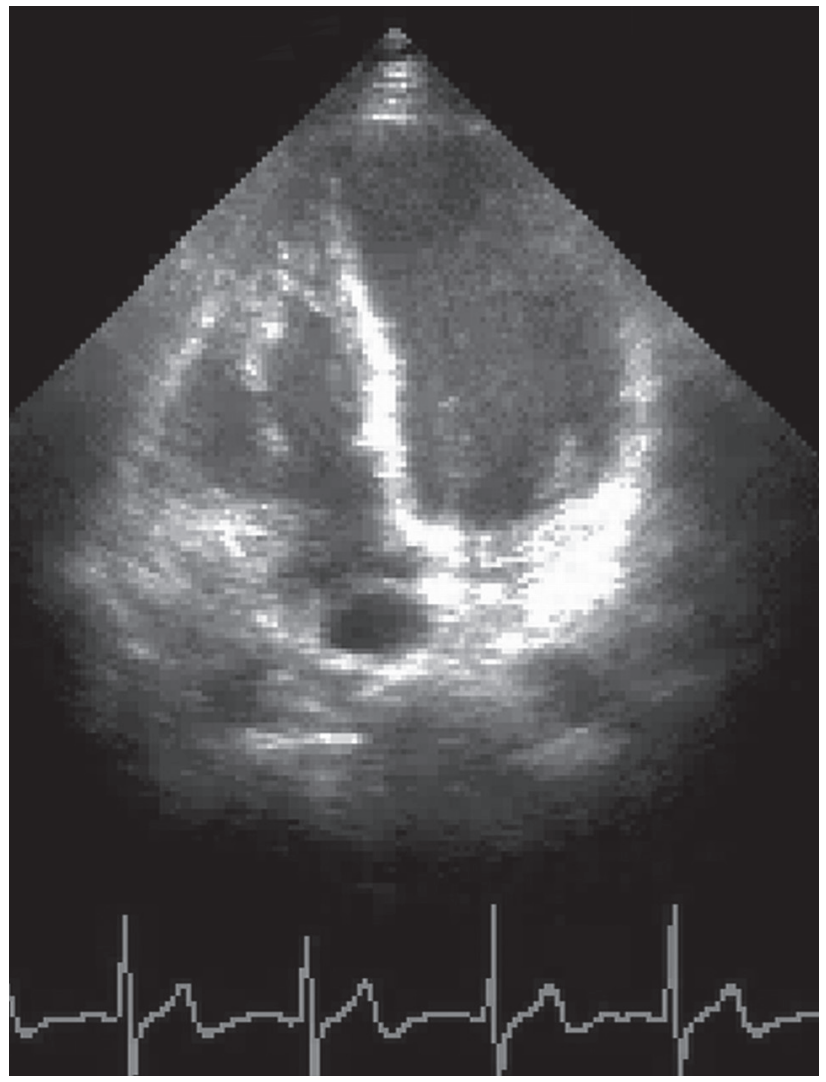

Fig. 3: Follow-up echocardiography which was performed one month later revealed disappearance of right ventricular thrombus 


\section{Discussion}

Cardiac involvement is rarely seen in Behçet's disease; however, presence of cardiac manifestations shows poor prognosis (4). Approximately $7-29 \%$ of cases with BD experience cardiac manifestations (5). Cardiac involvement which were seen in BD are cardiomegaly, conduction system abnormalities, pericarditis, myocarditis and rarely myocardial infarction (6-7). Other rare abnormalities are occlusion of subclavian artery, occlusion of carotid artery, aortic arch syndromes and aneurysms of abdominal aorta (8).

The mechanism of thrombus in BD is not well known. But it is believed that ischemia of endothelial cells leads to enhancement of platelet aggregation (9). And another possible mechanism of thrombus formation in $\mathrm{BD}$ can be the presence of antiphospholipid antibodies which was reported in $18 \%$ of cases (10). But in our case the antiphospholipid and anticardiolipin antibodies were negative. However, MTHFR mutation was homozygotes which was associated with hyperhomocysteinemia and prothrombine $20210 \mathrm{~A}$ mutation test was heterozygote. These mutations may be the possible cause of thrombus formation.

Treatment of thrombus with warfarin therapy in addition to oral steroid and immunsuppressive drugs have relation with disappearence of intracardiac thrombus in most patients. In literature 2 types of right heart thrombus were described; Type $A$ and $B$. In type $A$, thrombus is more mobile and large than type $\mathrm{B}$ and type $\mathrm{A}$ is associated with peripheral venous thrombosis and pulmonary embolism. Type B has small and nonmobile thrombus and it is associated with right heart abnormalities. The mortality rate is higher in Type A thrombus (11). In some cases immunsupressive drugs with concomitant warfarin treatment resulted as the regression of thrombus in type A patients.

We conclude that thrombus in right heart cavities can be seen in Behçet's disease and it can cause pulmonary thromboemboli. Behçet's disease should be in mind during conditions like in our case. Early echocardiogarphic examination will be advisable for detection of thrombus and can be helpful during follow-up. We also suggest the combination of oral steroid, cyclophosphamide and warfarin treatment for cardiac thrombus in patients with Behçet's disease.

\section{References}

1. Koc Y, Gullu I, Akpek G et al. Vascular involvement in Behcet's disease. J Rheumatol 1992; 19: 402-10.

2. Mogulkoc N, Burgess MI, Bishop PW. Intracardiac thrombus in Behcet's disease: a systematic review. Chest 2000; 118: 479-87.

3. Kaya EB, Yorgun H, Akdogan A et al. Heart-rate recovery index is impaired in Behcet's disease. Tex Heart Inst J 2009; 36: 282-6.

4. Wechsler B, Du LT, Kieffer E. [Cardiovascular manifestations of Behcet's disease]. Ann Med Interne (Paris) 1999; 150: 542-54.

5. Lie JT. Cardiac and pulmonary manifestations of Behcet syndrome. Pathol Res Pract 1988; 183: 347-55.

6. Baykan M, Celik S, Erdol C et al. Behcet's disease with a large intracardiac thrombus: a case report. Heart 2001; 85: E7.

7. Huong DL, Wechsler B, Papo T et al. Endomyocardial fibrosis in Behcet's disease. Ann Rheum Dis 1997; 56: 205-8.

8. Shimizu T, Ehrlich GE, Inaba G, Hayashi K. Behcet disease (Behcet syndrome). Semin Arthritis Rheum 1979; 8: 223-60.

9. Schmitz-Huebner U, Knop J. Evidence for an endothelial cell dysfunction in association with Behcet's disease. Thromb Res 1984; 34: 277-85.

10. Hull RG, Harris EN, Gharavi AE et al. Anticardiolipin antibodies: occurrence in Behcet's syndrome. Ann Rheum Dis 1984; 43: 746-8.

11. The European Cooperative Study on the clinical significance of right heart thrombi. European Working Group on Echocardiography. Eur Heart J 1989; 10 ; $1046-59$.

\section{Corresponding author:}

Uğur CANPOLAT, MD, Hacettepe University Faculty of Medicine, Department of Cardiology, Sihhiye/Ankara P.O.: 06100, Turkey; e-mail: dru_canpolat@yahoo.com 